\title{
CARL SCHMITT E A CRÍTICA À DEMOCRACIA LIBERAL
}

\section{CARL SCHMITT THE CRITIQUE OF THE LIBERAL DEMOCRACY}

\section{Roberto Bueno*}

Sumário: Introdução; 1 Crítica à democracia parlamentar; 2 A verdade, liberalismo e a crítica ao processo parlamentar; 3 Liberalismo, democracia e ditadura em Schmitt; Considerações finais; Referências.

\begin{abstract}
Resumo: Este artigo ocupa-se da releitura Schmitt a partir de suas críticas ao liberalismo que recentemente foram intensamente retomadas por amplos setores de intelectuais de esquerda como Mouffe. Esta tradição focalizou debilidades da democracia liberal que provocou debate que resultou na elaboração de um discurso que polarizou atenções com a ocupação da esfera pública por um tipo cidadão que substitua o consumidor político e que contribua para a criação de um conceito do político. Para este efeito a tradição de esquerda tenta retomar os conceitos-chave da crítica schmittiana à liberal-democracia. Este tipo de argumento permite aprofundar tanto quanto possível a compreensão das críticas à democracia e ao liberalismo em seu sentido reacionário e de efeitos totalitários à democracia ocidental com a qual usualmente trabalhamos.

Palavras-chave: Carl Schmitt. Liberalismo, Democracia. Constitucionalismo. Esquerda. Parlamentarismo. Representação política.

Resumen: This article takes care on the rereading of Schmitt since his critics to liberalism which was recently intensively recovered by the wide circles of leftist intellectuals as Mouffe. This tradition focus the weakness of the liberal democracy which induces the debate resulting in the elaboration of a speech wich polarizes the attentions with a kind of citizenship which occupies the public sphere that substitutes the political consumer and contribute to the creation of a concept of politics. To this purpose the leftist tradition try to retrieve the schmittian's key concepts of his critics to the liberal democracy. This kind of argument allows to go so deeper as possible at the understanding on the critics to democracy and liberalism in its reactionary sense and totalitarian effects to the real occidental democracy with which we usually work.
\end{abstract}

Key Words: Carl Schmitt. Liberalism. Democracy. Constitucionalism. Left. Parlamentarism. Political representation.

\section{INTRODUÇÃO}

Neste artigo focaremos basicamente de duas linhas de reflexão sobre Schmitt, em que uma delas possui um viés conceitual e a outra um perfil crítico-pragmático das instituições. Uma delas diz respeito a que em algum momento histórico a ideia de que o final das ideologias e o fim da história poderia ter afirmado o triunfo do liberalismo e de suas instituições. Dentre os seus desdobramentos observa-se que as instituições passam a ser compreendidas como passíveis de ser regidas consoante a lógica de uma administração neutra (apolítica) e eficiente, paralelamente a compreensão do cidadão como mero consumidor político.

Desde este prisma a vida pública resta esvaziada. Este processo suscitou a preocupação de alguns segmentos de esquerda. De forma mais ou menos intensa houve a preocupação com a reformulação de um discurso capaz de instrumentalizar o retorno ao político e da reocupação da esfera pública por uma figura cidadã, substituto do mero consumidor político. Nosso propósito é avaliar como Schmitt pode ser retomado, se isto se demonstrar possível, e ter seus conceitos-chave utilizados para realizar a crítica da democracia contemporânea. Uma segunda reflexão ocupa-se da retomada parcial dos

\footnotetext{
* Professor Doutor Adjunto I da Faculdade de Direito da Universidade Federal de Uberlândia (UFU) das disciplinas do Curso de Graduação (Teoria do Estado e Democracia; Filosofia do Direito, Filosofia Política) e do Programa de Pós-Graduação em Direito Público. Doutor em Filosofia do Direito pela Universidade Federal do Paraná (UFPR) (2011). Mestre em Filosofia do Direito e Teoria do Estado pela Fundação de Ensino Eurípides Soares da Rocha (2006). Mestre em Filosofia pelo Programa de PósGraduação em Filosofia da Universidade Federal do Ceará (UFC). Mestre em Filosofia pelo Programa de Pós-Graduação em Filosofia da Universidade Federal do Ceará (UFC). Especialista em Ciência Política e Direito Constitucional pelo Centro de Estudos Constitucionais de Madrid (CEC) (1994). Graduado em Direito pela Universidade Federal de Pelotas (UFPEL) (1992).
} 
conceitos-chave de Schmitt, de sorte que estes elementos possam restar mais claros como instrumentos crítico-analíticos necessários à primeira reflexão aqui proposta.

\section{CRÍTICA À DEMOCRACIA PARLAMENTAR}

A este respeito, na quadra histórica que mais lhe favorecia ao desenvolvimento das teses totalitárias que lhe subjaz à obra, e me refiro especificamente à Sobre a diferença entre sistema parlamentar e democracia, publicação datada de 1926, mas que tem início ainda antes, em torno do início dos anos 20 cuja primeira publicação é ainda do ano de 1923. Neste momento nos dizia Schmitt, "as diferenças entre as idéias liberalparlamentaristas e as democráticas de massa não podem mais passar despercebidas" (SCHMITT, 1996a, p. 4). A crítica ao sistema parlamentar levada a termo por Schmitt é, sobretudo, histórica e, principalmente, demolidora. A crítica estava inserida em contexto político-social weimariano no qual dialogava, e se opunha teoricamente a Kelsen tanto quanto a Smend e Heller, dentre outros menos conhecidos entre nós, mas célebres naquele momento histórico, como Richard Thoma e Gerhard Anschütz. ${ }^{1}$ Tem em vista a organização parlamentar weimariana e todas as vicissitudes que, em alguma medida, corroboraram as condições de surgimento e tomada do poder pelo nacionalsocialismo.

A crítica diversionista de Schmitt, contudo, está centralizada em uma política idealizada, em condições de debate e embate político que não tem condições de realizabilidade. Schmitt parte em sua acre crítica do suposto não irreal, mas cujo inverso é irrealizável, de que a política tornou-se ocupação de gentes desprezíveis, alvo de negociatas, atividades desenvolvidas no âmbito de um Parlamento cuja autenticidade de funções não pode mais ser detectada, dado que a discussão que ali tem lugar distanciase da seriedade e do interesse público e centra-se, isto sim, nas negociações. $O$ liberalismo encontra em sua natureza na discussão, na transigência e na negociação e, em suma, que se trata da transmigração da batalha sangrenta para a eternização do debate na órbita parlamentar ( $c f$. SCHMITT, 1996b, p. 128): o patos liberal se volta contra a violência e a falta de liberdade ( $c f$. SCHMITT, 1992, p. 98). O liberalismo marca a continuidade dos debates que marca a crítica de $S$ chmitt ao regime parlamentar liberal ( $c f$. STRONG, 2007, p. XIV), evidenciando aqui sua declarada influência de Donoso Cortés.

Assim, "o essencial do Parlamento [que] é [...] a discussão pública de argumentos e contra-argumentos, [d]os debates e conversações públicas e a parlamentação [...]" (SCHMITT, 1996a, p. 34), locus de deliberação onde, supõe a teoria liberal, encontra-se a possibilidade de "obter a verdade relativa num processo discursivo" (SCHMITT, 1996a, p. 45), que para Mouffe é "o princípio liberal fundamental" (MOUFFE, 1992, p. 2) em Schmitt. Este conceito se projeta sobre o resultado do processo legislativo sob a forma de leis justas. Este debate é o único ponto de apoio suficiente para, segundo a teoria liberal, a lei geral tem como pressuposto a sua conquista através da "mediação balanceadora e discussão pública" (SCHMITT, 1996 a, p. 46), ideia da qual, desde logo, o autor discordaria visceralmente, apoiador da ordem concreta ao contrário da lei geral criada em bases discursivo-parlamentares.

É importante destacar que quando Schmitt se opõe ao mecanismo parlamentar de debates ele o faz perfeitamente ciente da teoria lockiana segundo a qual a discussão vem para substituir a força ( $c f$. SCHMITT, 1996a, p. 47), ou seja, que "the law gives authority". Nos termos propostos por Schmitt, trata-se de uma aplicação em grandes lutas previstas por um de seus mais influentes pensadores, a saber, Donoso Cortés ( $c f$. SCHMITT, 1996a, p. 64), e também em conexão com a filosofia de Sorel. O fato de que 
a força venha adquirir maior papel em Schmitt permite que possamos vislumbrar que os processos de barbárie que sucederiam por meio das formas político-institucionais às quais a Alemanha foi aderindo não lhe poderiam ter resultado, de forma algum, inesperadas ou imprevisíveis.

Esta previsibilidade em Schmitt é uma ideia que se vê reforçada ao menos por dois argumentos. O primeiro deles é sua apropriada leitura de Sorel. Em um dos trechos em que trabalha o autor em seu texto Situação intelectual do sistema parlamentar atual, Schmitt interpreta Sorel como filósofo que odeia o intelectualismo e uniformização mas que, por outro lado, exige disciplina e moral rígidas ( $c f$. SCHMITT, 1996a, p. 66). Paralelamente, retoma a ideia de que a perspectiva de grandes batalhas apontam para que em seu cerne teremos uma acumulação de forças heróicas, de que presenciaremos a liberação de forças individuais nas massas sublevadas ( $c f$. SCHMITT, 1996a, p. 66). Toda esta força é criadora e, enfim, argumenta Schmitt, devido a sua espontaneidade das massas entusiasmadas, será diferente da ditadura ( $I b$.). É notável como parte desta argumentação se fará presente no desenvolvimento da obra de Schmitt. Observe-se, exemplificativamente como a ideia de espontaneidade das massas entusiasmadas pode ser aproximada ao conceito schmittiano de consulta popular direta que resolve-se na ideia de plebiscito, por intermédio do qual tem lugar a aclamação popular, faz a ligação entre o desejo popular e a atuação do líder político. $\quad \mathrm{O}$ segundo argumento trata de manifestação de Schmitt de que "todas as instituições tirânicas baseiam-se no centralismo e na autoridade”. (SCHMITT, 1996a, p. 63).

Em boa parte da crítica que se observa no discurso schmittiano é que toda a realidade da vida parlamentar, e também político-partidária, mostra-se absolutamente divergente daqueles que foram seus fundamentos legitimatórios. Esta divergência aponta para a possibilidade de que Schmitt construa o discurso de que

\footnotetext{
[...] as grandes decisões políticas e econômicas que determinam hoje os destinos das pessoas não são mais (se é que foram algum dia) o resultado de um balanceamento de opiniões, num discurso e contradiscurso público, e não são o resultado de debates parlamentares. [...] do jeito como estão as coisas hoje [...] é praticamente impossível trabalhar de outro modo senão por meio de comissões [...]. Assim elimina-se o plenum do Parlamento [...] sua condição de algo público [...] transformando-o necessariamente numa simples fachada. (SCHMITT, 1996 a, p. 47).
}

A crítica do autor reside, precisamente, em que as atividades do Parlamento já não se dão no plenário, mas sim em comissões ( $c f$. SCHMITT 1996a, p. 20-21), em círculos fechados ou de acesso bastante restrito. Em suma, se trata de que as decisões que realmente importam e que não raro envolvem altos interesses que afetam grandes multidões "são tomadas sempre em reuniões secretas de dirigentes de facções ou até mesmo nos comitês extraparlamentares" (SCHMITT, 1996a, p. 21). Schmitt, logo a seguir se insurge contra o fato de que o sentimento de justiça popular se insurge contra a tomada de decisões que a tantos atingem de forma secreta ( $c f$. SCHMITT, 1996a, p. 48). Contudo, haveremos de questionar diretamente sobre qual foi o tipo político que o autor, já em seu período de maturidade apoiou, ou seja, que o nacional-socialismo e sua teoria dos poderes do Führer não se representaram nada mais do que a suprema agudização deste processo de tomada de decisões de forma secreta e, ainda mais, com a manipulação da opinião pública ou, quando necessário, do extermínio dos divergentes, inimigos cuja designação era atributo e competência do Führer realizar.

A crítica de Schmitt se centra, portanto, em que o sistema parlamentar se havia transformado em uma mera fachada daqueles propósitos que o liberalismo, por excelência, defendia, a saber, que todo o processo de surgimento da averiguação dos 
anseios políticos populares pudessem ser averiguados nesta órbita. Habermas, por sua vez, ressalta que o parlamentar individual é membro de um partido e que suas decisões se darão "em função da facção a que ele pertence" (HABERMAS, 1984, p. 240). Desta forma, o argumento é de que o "Parlamento tende a se tornar num local em que esses funcionários do partido, presos a mandatos, se encontram par fazer com que sejam registradas decisões já tomadas". (HABERMAS, 1984, p. 240).

Contudo, talvez o principal problema que liga a argumentação de Schmitt a de Habermas é de que o primeiro, efetivamente, desconsidera a possibilidade de que o diálogo, no caso parlamentar, possa resolver por meio de compromissos racionais ou negociados as grandes questões sociais de um tempo ( $c f$. AGESTA, 1989, p. 10) ou, como disse Schmitt em seu momento, que na teoria liberal burguesa, ao Parlamento caberia analisar e resolver as questões sociais "num debate racional e aberto" (SCHMITT, 1996a, p. 49). Para Schmitt, marcado pela influência de Donoso Cortés, contudo, a burguesia encontra sua atividade marcada pela discussão, em suma, é uma "clase que discute", é "una clase discutidora" (SCHMITT, 1996b, p. 125), verdadeira religião que consiste na liberdade de discurso e de imprensa ( $c f$. SCHMITT, 1996b, p. 128), em que resta clara a percepção da esterilidade deste processo. Delineado este perfil de composição e funcionamento do Parlamento na concepção liberal-burguesa, Schmitt a utiliza para demarcar o terreno de não funcionamento da ágora parlamentar, até então tida como um cenário ideal do funcionamento do político, mas que em absoluta não encontraria acolhida na teoria schmittiana.

Desde logo, Schmitt já houvera, como ressalta Habermas, mencionado tal realidade durante a República de Weimar mas, isto sim, nosso questionamento é se a democracia pode, essencialmente, funcionar de forma virtualmente diversa considerando tanto sua estrutura representativa quanto o perfil dos representantes políticos assim como dos participantes do jogo político, entendendo-se aqui tanto eleitores quanto eleitos e toda a máquina estatal e partidária envolvida no processo eleitoral.

Retomando parte da argumentação schmittiana, malgrado sua crítica às negociações e/ou negociatas políticas, o autor não realiza um chamamento pela ética na política (muito menos uma ética normativa universalisante), ${ }^{2}$ algo que fica evidente, por exemplo, quando recorre a De Maistre para apoiar sua ideia de que mais importante do que a maneira, e sentido, como as decisões sejam tomadas é que elas, efetivamente, sejam tomadas ( $c f$. SCHMITT, 1996b, p. 123). Esta ideia é igualmente compartilhada por Strong ao dizer-nos que "Schmitt wants here to remove from politics [...] any possibility of justifying one's actions on the basis of a claim to universal moral principles". 3 (STRONG, 2007, p. XXII). Significativa parte do argumento schmittiano em favor de uma outra concepção de democracia oposta à liberal encontra-se na defesa de uma democracia substancial contraditoriamente aquela defendida pelo liberalismo que consta de uma teoria relativista e pluralista que, de forma bastante congruente, não reconhece mais do que o valor de uma teoria procedimentalista. Esta oposição se revelou claramente no embate teórico entre Schmitt e Kelsen, onde o primeiro posicionava-se a favor de uma democracia baseada na homogeneidade e na defesa da existência de uma concepção de verdade em oposição à Kelsen, para quem a heterogeneidade encontrava-se ligada intimamente à ideia de que a verdade não pode ser alcançada de forma fundamentada, senão por mero ato de imposição, algo com o qual seu pensamento político nunca se mostrou conforme. ${ }^{4}$

Desde logo, esta ausência de preocupação não parece encontrar-se no pensamento de Mouffe ( $c f .1999$, p. 155), pois, diz ela, o que está em jogo é a nossa capacidade para pensar a ética da política ( $c f$. MOUFFE, 1999, p. 158). Contudo, não é 
esta, desde logo, uma preocupação presente em Schmitt ao longo de sua obra. Mouffe chama a atenção para que Schmitt dedicara atenção à necessidade de valores políticos comuns em uma democracia ( $c f$. MOUFFE, 1999, p. 160) mas, contrariamente, acreditamos que Schmitt ao que se propõe é a imposição de um conjunto de valores inspirados em uma visão teológico-política, conexão esta que vê bastante clara ( $c f$. SCHMITT, 1992, p. 91).

Neste sentido entendemos que Schmitt não tem como preocupação, como veríamos adiante, a construção de qualquer sistema normativo, da sugestão de um viés ético para o exercício da política parlamentar. A rigor, esta crítica schmittiana acerca da incapacidade parlamentar para articular interesses que não aqueles próprios dos representantes eleitos anunciam a transformação do Parlamento em um "simples meio prático-técnico" (SCHMITT, 1996a, p. 10), circunstância em que, por conseguinte, "o Parlamento, então, estará liquidado" (Ib.). Um dos eixos da crítica de Schmitt ao Parlamento é de que encontra-se baseado em dos princípios, a saber, o princípio da publicidade e o governo por intermédio da discussão ( $c f$. AGESTA, 1989, p. 10), ambos amplamente negados pelas práticas parlamentares daquela quadra histórica alemã.

Em suas críticas focalizava que o Parlamento já não mais encontra seu lugar para o exercício de suas funções precípuas devido a que as discussões que ali tem lugar não o são por pessoas predispostas a se deixar convencer mas, antes, partem de interesses egoísticos ( $c f$. SCHMITT, 1996a, p. 7) e que, como ressalta Mouffe, que as "democracias liberales surgen hoy del hecho de que se ha reducido la política a simple actividad instrumental, a la persecución egoísta de intereses privados" (MOUFFE, 1999, p. 155). Todos estes interesses que medeiam a ação político-parlamentar Schmitt a faz acompanhar devidamente de "falatórios e de explanações". (SCHMITT, 1996a, p. 7).

Este é o pressuposto teórico que Schmitt apresenta para logo desenvolver sua crítica à representação nas modernas democracias de massas. Como nos recorda Mouffe, para Schmitt a representação apresenta-se como o "aspecto não democrático deste tipo de democracia" (SCHMITT, 1996a, p. 148-149). O que é mais, Schmitt propõe em sua Teologia Política que, na qualidade de democracia encontra boa e acertada definição em que ela é a "identidade entre governantes e governados" (SCHMITT, 1996a, p. 15) ou, ainda em outras palavras, que "a moderna democracia de massas procura concretizar uma identidade entre governantes e governados e, portanto, enfrenta o Parlamento como instituição obsoleta e inconcebível" (SCHMITT, 1996a, p. 16). Contudo, é precisamente contra o processo de representação política que o autor se volta, dado que não compreende viável este processo de identificação quando o Parlamento e seus representantes apresentavam-se nestas novas condições que a democracia de massas lhes apresentava.

Neste contexto alinhado por Schmitt, a rigor, as negociações e decisões tomadas nos termos em que Bobbio em algum momento denomina de "poder invisível" com agudez a crítica não apenas à falta de transparência do poder político nas democracias contemporâneas como, e talvez principalmente, pela institucionalização do distanciamento do processo de tomada de decisões daqueles que detém o poder político (soberania) em última análise.

A estrutura dos partidos políticos para Schmitt não traduzia mais do que a organização dos interesses particulares daqueles que, publicamente, compunham um corpo de representantes políticos. A rigor, nos diz ele

[...] os partidos [...] atualmente não se apresentam mais em posições divergentes, com opiniões passíveis, mas sim como grupos de poder sociais ou econômicos, que calculam os interesses e as potencialidades de ambos os 
lados para [...] selarem compromissos e formarem coalizões. (SCHMITT, 1996a, p. 8).

Para Schmitt restava clara a inoperância fundamental da estrutura políticoparlamentar. Os grandes princípios que lhe inspiravam, tais como o da publicidade e o da discussão encontravam-se privados de aplicabilidade prática, isto sim, mantendo apenas a aparência de funcionalidade. Os Parlamentos, portanto, como nos diz Agesta, "no mantienen grandes discusiones en sus Plenos, sino que trabajan mediante pequeños comités, que, por su propia naturaleza, rehúsan la publicidad" (AGESTA, 1989, p. 10). Não é pouco atribuir ao Parlamento esta função de manter o real exercício do político longe dos olhos do público, algo que, posteriormente, viria a ser alvo da atenção de Bobbio, como veremos, quando aborda o conceito de transparência e visibilidade do político. Desde a ótica de Schmitt poderíamos questionar até quando será possível manter a fachada liberal de uma estrutura que foge à retórica legitimatória?

\section{VERDADE, LIBERALISMO E A CRÍTICA AO PROCESSO PARLAMENTAR}

Para melhor compreender a crítica schmittiana ao parlamentarismo deveremos atentar ao conceito de liberalismo. ${ }^{6}$ Entendemos ser ele importante para entender a crítica de Schmitt ao parlamentarismo posto que contém uma concepção acerca da construção do conceito de verdade que repercutirá no funcionamento das instituições parlamentares. Tendo em vista que o liberalismo encontrava-se conceitualmente próximo da democracia, Schmitt admite que "no século XIX, o sistema parlamentar e a democracia estavam tão interligados que foram considerados como tendo o mesmo significado" (SCHMITT, 1996a, p. 31-32). Esta ideia está intimamente ligada à percepção de que o liberalismo compreende o parlamentarismo como uma instância capaz de trazer ao cenário atores capazes de discutir publicamente e, ademais, deliberar racionalmente a partir de argumentos e contra-argumentos que conduzam à verdade, na melhor linha liberal e iluminista que remete, por exemplo, a autores tão pouco caros à Schmitt como John Stuart Mill.

Este seria o processo racional que, segundo Habermas, está presente em Schmitt como desembocando na construção normativa que sintetiza a lei, em suma, não na voluntas, mas na ratio ( $c f$. HABERMAS, 1984, p. 101). Para Schmitt, contudo, não lhe servirá o velho adágio de que "veritas non auctoritas facit legem" - verdade esta surgida dos debates parlamentares - mas, isto sim, o seu inverso, ou seja, de que a autoridade é quem, e aí valendo-se de um de seus clássicos prediletos, Hobbes, realmente faz a lei, compondo, desta forma, sua leitura da soberania ${ }^{7}$ e da legitimação do poder político do Führer. A legitimação do poder do Führer parece residir em parte na teoria do mito, no perfeito ajustamento entre a vontade do povo e na ação do Führer. Como recorda Schmitt a este respeito, Mussolini sustentava que o mito era uma crença e que, como tal, "não precisa ser uma realidade, ele é estímulo e uma esperança, crença e coragem" (apud SCHMITT, 1996a, p. 70).

Tendo em vista a contraposição liberal acerca da afirmação do processo de emersão da verdade por meio de debates parlamentares à realidade política weimariana de seu tempo, Schmitt irá dizer ser possível posicionar-se contrariamente à crença de um Naumann, um Weber e um Preuss, dizendo que já ninguém mais compartilhava suas crenças de que o Parlamento pudesse formar uma elite política e, por conseguinte, articular-se como a grande tribuna política ( $c f$. SCHMITT, 1996a, p. 9). Portanto, já não mais se trata de arregimentar argumentos em prol da verdade ou de uma atitude que 
mereça o reconhecimento de correta mas, isto sim, "de conquistar a maioria, para poder exercer o poder por meio dela". (SCHMITT, 1996a, p. 8).

Schmitt retoma Hegel para destacar que este abordava a questão da opinião pública sob a ideia de que possuía um valor educativo, ou seja, que por meio dela o "povo aprende a conhecer a verdade continuada em seus interesses" (SCHMITT, 1996 a, p. 45). Mesmo tendo esta tese hegeliana como um de seus pontos de apoio teórico, Schmitt entende que a política parlamentar em crise dispensa a argumentação devido a que pode granjear apoios baseados em técnicas de propaganda, tanto quanto de "manipulação da opinião pública [...] tão antigas quanto a própria democracia" (SCHMITT, 1996a, p. 27), algo para o que as invenções técnicas e o próprio conceito de técnica se prestam perfeitamente segundo a crítica schmittiana. ${ }^{8}$

Ainda quando a leitura da tese hegeliana por Schmitt deixe claro que a opinião pública tem o caráter de permitir ao povo conhecer a verdade, logo, Schmitt não terá como um elemento importante assegurar que a opinião pública possa ser autonomamente e criada. ${ }^{9} \mathrm{O}$ autor não apenas reconhece que há técnicas de propaganda que manipulam a opinião pública como, mais gravemente, pouco se interessa pelo tema da preservação de instrumentos que garantam a formação independente da opinião pública. Mas quanto à realização prática desta influência podemos retomar de Schmitt sua ideia que reforça que a técnica efetivamente presta-se ao uso político e, ainda mais precisamente, que "toda política forte há se de servir dela" (SCHMITT, 1992, p. 119). Portanto, a teoria schmittiana irá incorporar esta perspectiva do uso da técnica para "políticas fortes", congruente com o desenvolvimento que sua teoria política teria nos anos subseqüentes.

Esta percepção de Schmitt sobre quão antiga é a possibilidade de manipulação com apoio da técnica não converge com a leitura do tema realizada pelo Iluminismo, cujo entendimento é de que a opinião pública esclarecida é capaz e hábil para tornar impossíveis os abusos ( $c f$. SCHMITT, 1996a, p. 37). Em suma, o "argumento [...] característico da discussão autêntica, desaparece" (SCHMITT, 1996a, p. 8). ${ }^{10}$ A este respeito há que ressaltar dois aspectos. O primeiro, é de que Schmitt entende que à raiz do Iluminismo encontra-se um racionalismo febril, e ingênuo, ${ }^{11}$ século XVIII que encontrava seu patos específico no mítico conceito de virtude ( $c f$. SCHMITT, 1992, p. 109), cujo estado não lhe permite enxergar diante de si nada mais do que "aquele paraíso idílico vislumbrado pelo otimismo ingênuo do Iluminismo" (SCHMITT, 1996a, p. 59), ${ }^{12}$ caracterizado pela crença na possibilidade de aperfeiçoamento intelectual e moral da humanidade ( $c f$. SCHMITT, 1992, p. 100), embebido na noção de progresso como esclarecimento e aperfeiçoamento moral ( $c f$. SCHMITT, 1992, p. 111). Por outro lado, o autor se opõe ao economicismo proveniente das hostes do pensamento marxista do século XIX ao qual não recepciona favoravelmente também por sua desconsideração da importância da tradição e ao declínio do elemento espiritual ${ }^{13}$ ao qual, por certo, colaborava de forma importante o novo mundo de uma evolução técnica sem precedentes que permitia à alma alemã o sentimento de desamparo e impotência ( $c f$. SCHMITT, 1992, p. 117).

Acerca da argumentação em torno da discussão há ainda um segundo elemento a avaliar. Resta claro que Schmitt nega a possibilidade de que o assinalado processo de debate público inspirado no otimismo do Iluminismo possa realmente ocupar um lugar de modo frutífero e, antes, seria contraposto por uma teoria do emprego direta da força (cf. SCHMITT, 1996a, p. 60).

Mas se as críticas ao parlamento veem seu tom elevar-se, em parte isto se deve à elevação de demandas por direitos nem sempre alcançáveis por coletivos que se dispõe apenas a usufruir direitos sem sufragar, de alguma forma, os gastos que isto supõe, e 
nem mesmo empregar os necessários esforços para lograr os indispensáveis arranjos políticos para que se cumpram tais finalidades políticas por intemédio do mundo do direito. Em algum momento invertia-se a lógica da não-intervenção do Estado liberal por uma nova percepção de que o Estado haveria de cumprir mais e mais extensas funções, que Schmitt chegaria a entender como um Deus ex machina ( $c f$. SCHMITT, 1996b, p. 110). O problema que nos ocupa é que o Parlamento perdeu espaço em prol das atividades do Executivo, órgão quem em Schmitt deterá o poder decisório e a guardar de segredos do Estado ( $c f$. SCHMITT, 1996a, p. 43). O alargamento das funções do Estado último com vistas a cumprir as demandas populares tornaram o Parlamento a principal arena de organização política em detrimento da órbita do Legislativo, que restou esvaziada.

\section{LIBERALISMO, DEMOCRACIA E DITADURA EM SCHMITT}

Outro dos centros conceituais em torno dos quais a teoria schmittiana gravita é o liberalismo. Segundo Schmitt a teoria liberal concentra-se na luta política interna e, muito precisa e especialmente, na luta contra sua intrínseca desconfiança acerca da expansão do poder estatal ( $c f$. SCHMITT 1992, p. 97), crítica que visa fundamentalmente transformar o Estado em um agir compromissado com princípios que concedem a supremacia aos interesses e liberdades individuais, determinando que $o$ indivíduo seja tanto seu terminus a quo quanto seu terminus ad quem. ${ }^{14}$

Este triunfo do individualismo liberal inverte a tradição hegeliana do Estado no século XIX em que o Estado aparecia como o reino da eticidade triunfante e impondo-se sobre um reino animal e egoísta. A afirmação do liberalismo contraditará esta tese e entronizará a sociedade e o indivíduo como titulares de direito perante uma realidade estatal já não mais concebida como suprema eticidade possível. Invertidos os papéis, as teorias acerca da natureza do Estado são igualmente invertidas, passando a ocupar espaço predominante uma visão pessimista sobre o seu desempenho, daí que a teoria liberal se preocupe notavelmente em limitar-lhe o poder e limites de ação.

O liberalismo necessariamente haveria de ser um dos alvos teóricos de Schmitt devido a vários de seus pressupostos teóricos. Um destes elementos liberais é o do enfoque na autonomia individual ( $c f$. STRAUSS, 2007, p. 101-102). A filosofia política de Schmitt, desde logo, enfatiza antes o exercício do poder concentrado e a dependência política do que a criação de esferas autônomas tanto individual quanto coletivamente. Um outro elemento que opõe Schmitt aos princípios liberais diz respeito ao fato de que o liberalismo entroniza a proteção ao indivíduo bem como às liberdades em sentido amplo, é teoria que se opõe conceitualmente à violência (Gewalt) ( $c f$. SCHMITT, 1992, p. 100; $c f$. STRONG, 2007, p. XV) que um Estado totalitário projeta como política. Assim, Schmitt reconhecerá que o próprio patos ético do liberalismo é sua luta "contra a violência e falta de liberdade" (SCHMITT, 1992, p. 98), é a transformação da luta propriamente dita em concorrência e discussão ( $c f$. SCHMITT, 1992, p. 98). Strong identifica que a abordagem do liberalismo não apenas denota esta preocupação com os direitos e liberdades como também a questão da estrutura do poder e da dominação (cf. STRONG, 2007, p. XIX), tema que resultará não apenas bastante caro como central no desenvolvimento da teoria política schmittiana.

A ideia de luta na teoria liberal é posta segundo os termos de Benjamin por meio de sua verificação de que a guerra e, em sentido amplo, toda violência, é carente de qualquer utilidade ( $c f$. SCHMITT, 1992, p. 102). Este desenvolvimento teve lugar uma vez que amplamente oposta aos interesses econômicos da burguesia emergente e reitora dos destinos políticos e econômicos do Estado moderno. 
A necessidade de ocupar-se da crítica ao liberalismo torna-se evidente quando temos em consideração que o autor virá a legitimar ações de Estado que possam sacrificar vidas quando as circunstâncias assim exigirem consoante a avaliação do soberano. Colocada a crítica ao liberalismo nestes termos, resta-nos examinar como é aberto o passo aos conceitos de democracia e ditadura na particular concepção de Schmitt sobre ambos. Em verdade, a democracia encontra-se oposta é ao liberalismo conquanto este último impede, devido à sua teoria da representação, a identidade entre governante e governado, concepção central para a ideia de democracia em Schmitt ( $c f$. MOUFFE, 1992, p. 2), o que lhe permite concluir que o liberalismo nega a democracia. Isto é o que torna possível entender porque Schmitt compreende que tanto o bolchevismo como o fascismo podem ser compatíveis com o seu particular conceito de democracia, ou seja, bastaria com que se pudesse verificar a existência desta identificação entre governantes e governados.

A ditadura surge em Schmitt como um conceito factível e em contato com o seu momento histórico. Projetavam-se por intermédio de Estados como a Itália e a Alemanha e seus grandes líderes partidários que eram colocados fora do cenário da disputa político-partidária. Contudo, o próprio autor destacava nos anos vinte, precisamente em 1923 em sua Situação intelectual do sistema parlamentar atual, que a ditadura the parecia ser uma "interrupção da continuidade do desenvolvimento" (SCHMITT, 1996a, p. 53). Ainda nestes primeiros anos da década de 20 não parecia que a filosofia de Schmitt estivesse totalmente voltada ao apoio do totalitarismo, como, progressivamente, veio a tornar-se a partir de pressupostos teóricos factíveis com tal desenvolvimento.

Há leituras de Schmitt que indicam que no período posterior à Primeira Grande Guerra Mundial o autor "era inquieto di fronte al prevedibile avvento di una dittadura nazionalsocialista" (BENDERSKY, 1989, p. 233). É sabido que Schmitt esteve atento e combativo à ditadura do proletariado proveniente do discurso socialista mas, por outro lado, e contrariamente à interpretação de Bendersky, entendemos que em sua obra há mostras suficientes acerca de sua receptividade à ditaduras de outro verniz teórico.

Por certo, Schmitt definia o Estado como "status político de um povo organizado numa unidade territorial" (SCHMITT, 1992, p. 43). Os líderes do Estado encontravamse em posição hierarquicamente superiores, detinham poderes de mando que desconstituíam a possibilidade de interferência parlamentar, não obstante a posição contrária de Bendersky, segundo quem "lo scopo di Schmitt non era quello di far diventare il presidente un dittatore sovrano al di sopra della costituzione" (BENDERSKY, 1989, p. 106). Isto remete a concepção de, mesmo por meio de uma figura dirigente forte, de um Estado onipotente que é uma superficial secularização "das fórmulas teológicas da onipotência de Deus" (SCHMITT, 1992, p. 68). Com isto projeta-se de modo claro que a posição dos parlamentos seria a de um cenário em que os atores poucos diálogos teriam a pronunciar e, em caso de tê-los, seriam de escassa audição e projeção nas decisões políticas.

Em circunstâncias como estas o Parlamento ocuparia um papel de cenário de uma democracia mas, isto sim, sem ocupar as funções de um locus de debate e decisões políticas, centralizadas, isto sim, na figura do Executivo. Em suma, como recorda Agesta, tínhamos naquele momento, em verdade, um Parlamento que "era más um teatro que um foro, en que hay partes que se limitan a recitar papeles estudiados y convenidos fuera del propio Parlamento". (AGESTA, 1989, p. 12).

Presente este conceito de ditadura, Schmitt irá ocupar-se dos conceitos e liberalismo, democracia e das possibilidades de conexão e convivência de ambos com a ditadura. $\mathrm{O}$ autor entende a democracia como um conceito que pode conviver tanto com 
o militarismo como com o pacificismo, com o absolutismo ou com o liberalismo, bem como com versões do centralismo ou descentralização e, ainda, regimes políticos progressistas ou reacionários ( $c f$. SCHMITT, 1996a, p. 26) e, em suma, que "a ditadura não é o oposto da democracia" (SCHMITT, 1996a, p. 29), muito embora Schmitt a anteponha à discussão que é um elemento fundamental de nossa concepção contemporânea de democracia ( $c f$. SCHMITT, 1996b, p. 128). Em suma, a posição do autor é de que "a ditadura também não é o oposto decisivo da democracia, assim como esta não o é da ditadura". (SCHMITT, 1996a, p. 32).

Em Schmitt encontramos a tese de que o liberalismo nega a própria essência da democracia e, por sua vez, a democracia igualmente lhe nega ao liberalismo, algo que é reforçado na leitura realizada por Mouffe (ver MOUFFE, 1999, p. 147). Em verdade, Schmitt é um dos campeões da crítica ao liberalismo, Schmitt foi um "intérprete singular y máximo debelador de la cultura política demoliberal" (LUCAS VERDU, 1989 , p. 34), e sua retomada ao tempo em que pode aportar interessantes aspectos deve igualmente supor certas precauções quanto ao ponto de chegada de suas argumentações.

Em sua análise de Schmitt, alguns anos antes Mouffe da publicação de $O$ retorno do político já havia dedicado sua atenção ao fato de que em Schmitt "a preeminência do legislativo sobre o executivo não pertence ao universo do pensamento da democracia, mas ao do liberalismo" (MOUFFE, 1992, p. 1). Neste momento torna-se perceptível que o conceito de democracia manejado por Schmitt será fundamental para a compreensão e justificação de boa parte de sua teoria. Contudo, como veremos adiante, o conceito de democracia trabalhado por Schmitt dista muito daquele com o qual hodiernamente nos manejamos.

Mouffe ressalta com acerto com o alvo de Schmitt não é, em verdade, a democracia - cujo conceito, a dizer verdade, torce e retorce -, mas sim o liberalismo ( $c f$. MOUFFE, 1999, p. 152), cujo elemento de pluralidade não suporta nem admite sob qualquer circunstância. ${ }^{15}$ Outro de seus elementos que resultará definitivo para sua ferrenha oposição diz respeito a convicção teórica liberal acerca do processo de surgimento e legitimação das leis, a saber, por meio de debates no Parlamento que como bem ressalta Mouffe, resume-se na veritas, e não na auctoritas ( $c f$. MOUFFE, 1999, p. 152), concepção que, deveras, não lhe seria útil, senão todo o contrário.

Sua crítica a democracia representativa parlamentar lhe levará a argumentar em prol do exercício político direto por parte da população. $\mathrm{O}$ apoio à democracia direta por Schmitt tem seu ponto de arranque na argumentação de que originariamente a população arranjava para manifestar-se sobre todos os temas que lhe diziam respeito. Contudo, a complexidade das sociedades torna-se argumento para que Schmitt manipule a seu favor, ou seja, de que o Parlamento torna-se um elemento que teria advindo para suprir tal dificuldade e, ainda, como democrático. Ao atacar as debilidades do Parlamento Schmitt irá inclinar-se pelo retorno ao político, isto é, à fala e decisão direta por parte dos interessados, a saber, do povo. Em outros termos, irá defender a ideia da democracia plebiscitária em que, segundo seu esquema, a manifestação popular termina por concentrar todos os poderes na figura do aclamado. A aclamação funciona em Schmitt como a melhor forma de expressão democrática da vontade do povo ( $c f$. SCHMITT, 1996a, p. 17), situação na qual lhe resta claro o quanto o mecanismo parlamentar apenas sobrevive na qualidade de uma "máquina artificial" (Ib.).

Nestes termos Schmitt opõe-se à possibilidade de uma democracia (liberal) em que a diferença (de opiniões e tudo o mais), na qual o dissenso tenha vez e lugar possa encontrar o seu lugar. $\mathrm{O}$ mundo no qual Schmitt todavia respira e aspira é um em que o signo do teológico conduz o político sob o reino da homogeneidade. 
Dentro deste contexto temos de retomar o início de nossa argumentação ao expormos que para Schmitt o liberalismo e a democracia são antípodas. Paralelamente, e para uma inicial compreensão de seu conceito de democracia, ele acresce que a própria "ditadura não é o oposto da democracia" (SCHMITT, 1996a, p. 29). Haverá de ser este precedente antiliberal na filosofia de Schmitt o que lhe permitiria, de forma congruente, aderir ao nacional-socialismo ( $c f$. MOUFFE, 1999, p. 152) sem necessidade de realizar uma ruptura teórica. Não obstante possa talvez identificar-se a oposição schmittiana à teoria liberal como boa parte do atrativo de sua filosofia ao pensamento de esquerda, contrariamente a Schmitt, Mouffe ressalta aquele que ao seu entender é o principal valor do conceito de democracia liberal.

Não obstante certas restrições, a autora destaca que a democracia liberal possui um aspecto sempre inacabado, ou seja, que nos mantém a "impresión de estar [o futuro] incompleto y abierto [...]" (MOUFFE, 1999, p. 153), cujo cerne parece centralizar no valor milliano da liberdade individual que, segundo diz, é a "única libertad que merece tal nombre [...]" (MOUFFE, 1999, p. 165). Esta adesão de Mouffe a alguns dos mais caros princípios da democracia liberal expresso em vários momentos ${ }^{16}$ sugere que se distancia em grande parte da argumentação schmittiana ${ }^{17}$ mas que, paralelamente, continuaria apoiando a crítica mediadora apresentada por Agesta referente a teoria de Schmitt sobre o papel do Parlamento.

Por sua vez, segundo Agesta, não obstante algumas críticas de Schmitt mostrarem-se certeiras, por outro lado, "es más discutible la crítica de la capacidad del régimen parlamentario y del mismo Parlamento para crear o favorecer un proceso dialéctico de negociación [...]" (AGESTA, 1989, p. 10). Tendo em vista a adesão de Mouffe aos princípios mais caros da democracia liberal parece ser que não encontraria fortaleza nos argumentos de Schmitt a ponto de buscar argumentos para desconstituir o papel central do Parlamento mas, antes, para buscar elementos que, por um lado, lhe fortaleçam a atuação e as instituições de controle bem como lhe desconstituam os pontos débeis.

Em Schmitt a democracia opera sob o signo da igualdade dos iguais ( $c f$. SCHMITT, 1996a, p. 16), algo reforçado por Mouffe ao dizer-nos que neste autor encontramos o conceito de democracia ligado à defesa da ideia de que os iguais serão tratados de forma igualitária enquanto os desiguais não serão tratados de maneira desigual ( $c f$. MOUFFE, 1999, p. 147), ponto no qual retoma a lição clássica grega de Aristóteles. Em suma, como diz Schmitt, na verdadeira democracia o que se encontra implícito é que "não só o igual seja tratado igualmente, mas que, como consequência inevitável, o não igual seja tratado de modo diferente" (SCHMITT, 1996a, p. 10).

O que dizer, agora, das possibilidades de conexão e convivência do liberalismo e da democracia com o conceito de ditadura em Schmitt? O autor defende a ideia de que a democracia não contradiz a ditadura. Desde logo, haveríamos de ressaltar que o seu conceito de democracia não é o mesmo que habitual e comumente manejamos, de corte liberal, em nossos dias. Literalmente, segundo ele, a própria "ditadura não é o oposto da democracia" (SCHMITT, 1996a, p. 29), e isto haveria de constituir um precedente lógico e ideológico que tornaria viável e congruente sua posterior adesão formal e institucional ao nacional-socialismo sem necessidade de realizar uma ruptura teórica. Aparte esta conexão mencionada Schmitt retoma o argumento de Donoso de que o "momento da última batalha chegara: perante o mal radical, só existe uma única ditadura, e a ideia legitimista da sucessão passa a ser, num instante como esse, uma simples teimosia inócua". (SCHMITT, 1996b, p. 130).

Esta conexão teórica que lhe permitiria aderir ao nacional-socialismo nos faz recordar a previsão de Schmitt sobre um dos riscos que corria a democracia e o 
democrata. Oportunamente recordava o perigo de que a democracia "venha a ser utilizada para eliminar a democracia, por isso o democrata radical deve se decidir se continua sendo um democrata mesmo contra a maioria ou se renuncia a si mesmo" (SCHMITT 1996a, p. 28). Neste sentido poderíamos questionar se Schmitt poderia entender-se como um dos democratas que, na encruzilhada, haveriam de renunciar aos seus princípios como, de alguma forma, parece ser uma tese implícita ao que nos dizem Bendersky e, por fim, Mouffe. A rigor, nos parece o contrário, ou seja, que Schmitt encontra-se entre os detratores da democracia liberal que não necessitou "renunciar a si mesmo".

\section{CONSIDERAÇÕES FINAIS}

O compromisso do soberano com a lei em Schmitt encontra sua explicação quanto ao escasso grau de submissão devido a que o autor entende que mesmo a ordem jurídica se baseia em uma decisão e não em outra norma jurídica ( $c f$. SCHMITT, 1996b, p. 90), tese esta que havia sido sugerido Kelsen em sua teoria do direito conforme reconhecido por Kelsen ( $c f$. SCHMITT, 1996b, p. 97). Em suma, "a decisão [sobre o Estado de exceção] liberta-se de qualquer ligação normativa e torna-se, num certo sentido, absoluta" (SCHMITT, 1996b, p. 92). Este sentido absoluto do conceito de decisão em Schmitt remete à sua leitura dos contra-revolucionários e, sugerimos que, em especial, de De Maistre, para quem soberania significa essencialmente decisão. ${ }^{18}$ Mas bem, a este respeito acresce que o valor do Estado consiste em apresentar a decisão tal como o valor da Igreja em apresentar uma decisão inapelável.

Estabelecido o paralelo entre o político e o religioso, podemos recordar a conceituação de teologia aplicada à política em Schmitt. Aqui ficam postas as condições para a compreensão do poder soberano como infalível e, por conseguinte, para que, como finalmente conclui Schmitt, dizer que "toda soberania age como se fosse infalível, [e que] todo governo é absoluto" (SCHMITT, 1996b, p. 122). Aqui, portanto, podemos uma vez mais voltar à referência schmittiana de que o conceito de soberania possui em seu interior uma gritante conexão com o teológico ( $c f$. SCHMITT, 1996b, p. 116). Assim como no âmbito do teológico encontrávamos um Deus que governa o mundo de forma absolutamente incondicionada e independente, no âmbito do político o construtor do mundo segundo o liberalismo era o legislador. Para Schmitt, contudo, haveria de ser substituído este máximo poder do legislador pela figura do soberano, imbuído do poder de decidir.

Quando tratamos do Estado de exceção, portanto, haveremos de entender que as decisões nele tomadas haverão de representar nada menos do que a efetiva eliminação da norma ${ }^{19}$ (SCHMITT, 1996b, p. 92). Sendo assim, a normalidade da ordem jurídica encontrará seu termo quando o político avalia a presença das (subjetivas) condições de suspensão da ordem jurídica para fins de asseguramento da ordem política. Será esta uma decisão que, ao menos do ponto de vista teórico, haverá de projetar-se indefinidamente ao futuro?

De qualquer sorte, uma outra parte da argumentação de Schmitt procura ressaltar que o Estado de exceção e o processo decisório nele presente possui a característica de reimplantar uma ordem afetada. Capaz para avaliar o abalo que a ordem política tenha sofrido e as medidas para, vencido o caos, reinstaurar a ordem com vistas à retomada da aplicação da ordem jurídica é daquele reputado como soberano ( $c f$. SCHMITT, 1996b, p. 93). Paradoxalmente, Schmitt faz depender o conceito de exceção daquele de normalidade que pretende destruir. Menos do que contraditoriedade, a argumentação 
falaciosa schmittiana aparece no momento em argumenta que o Estado de exceção representaria nada mais do que um período intermediário até a volta à normalidade.

Neste período de vigência de excepcionalidade seriam reconstruídas as condições de normalidade política, que uma vez refeita, se encarregaria o Estado de exceção de auto-desconstituir-se. Neste momento Schmitt parece evocar a teoria marxista a qual tanto se opôs e, analogamente, argumentar que a ditadura do proletariado se auto-dissolveria em um privilegiado status libertatis todavia não conhecido. Ao gênio político perpassado de realismo que habitava ao raciocínio de Schmitt não lhe fugiria que a política real não se encarregaria de entregar o poder nestes termos.

\section{REFERÊNCIAS}

AGESTA, Luiz Sanchez. Sobre la crisis del regimen parlamentario en Carl Schmitt. Revista de Estudios Políticos (Nueva Época). Núm. 64, Abril-Junio, 1989, p. 7-23.

BENDERSKY, Joseph W. Carl Schmitt. Teorico del Reich. Bologna: Il Mulino, 1989. p. 369.

BOBBIO, Norberto. Teoria geral da política. A filosofia política e as lições dos clássicos. Rio de Janeiro: Campus, 2000. P. 720.

DYRBERG, Torben Bech. The leftist fascination with Schmitt and the esoteric quality of 'the political'. Philosophy \& Social Criticism. Vol, 35, 2009, p. 649-669. Disponível em: 〈http://psc.sagepub.com>. Acesso em: 10 de janeiro de 2010.

FIJALKOWSKI, Jünger. La trama ideológica del totalitarismo. Madrid: Tecnos, 1966. p. 354.

GUARDIOLA-RIVERA, Óscar. Tiempo de excepción: El extraño retorno de la religión en política. Isegoría. CSIC. $n^{\circ} .39,2008$, p. 227-237.

HABERMAS, Jürgen. Mudança estrutural da esfera pública. Rio de Janeiro: Tempo Brasileiro, 1984. p. 397.

KELSEN, Hans. La esencia y el valor de la democracia. Oviedo: KRK, 2006.

LOPEZ GARCIA, José Antonio. La presencia de Carl Schmitt en España. Revista de Estudios Políticos (Nueva Época), no 91, Enero-Marzo, 1996, p. 139-?.

LUCAS VERDU, Pablo. Carl Schmitt, interprete singular y Maximo debelador de la cultura político-institucional demoliberal. Revista de Estudios Políticos (Nueva Época). no. 64, Abril-Junio, 1989, p. 25- 92.

MOUFFE, Chantal. Pensando a democracia com, e contra, Carl Schmitt. Revue Française de Science Politique, vol 42, nº. 1, fevereiro, 1992, p. 1-14. Tradução Menelick de Carvalho Neto. Disponível em: <http://www.almg.gov.br/CadernosEscol/Caderno2/teoria.pdf $>$. Acesso em: 23 de março de 2010. 
The democratic paradox. London / New York: Verso, 2000.

El retorno de lo político. Comunidad, ciudadanía, pluralismo, democracia radical. Barcelona: Paidós, 1999. p. 207.

PICCONE, Paul; ULMEN, G. L. Introduction to Carl Schmitt. Telos, $\mathrm{n}^{\mathbf{0}}$ 72, Special Issue, 1987, p. 3-14.

SCHMITT, Carl. The Concept of the Political. Chicago \& London: The University of Chicago Press, 2007. p. 126.

Political Theology. Four Chapters on the concept of Sovereignty. Chicago: University of Chicago Press, 2006. p. 116.

Legalidad y legitimidad. In: AGUILAR Héctor Orestes. Carl Schmitt, Teólogo de la política. México: Fondo de Cultura Económica, 2001.

A crise da democracia parlamentar. São Paulo: Scritta, 1996a. p.133.

. Teologia Política. In: SCHMITT, Carl. A crise da democracia parlamentar. São Paulo: Scritta, 1996b. p. 82-130.

O conceito do político. Petrópolis: Vozes, 1992.

. Sobre el parlamentarismo. Madrid: Tecnos, 1990. 1987a.p.142.

Ex Captivitate Salus. Esperienze degli anni 1945-47. Milano: Adelphi,

Osservazioni in risposta a un discorso radiofonico di Karl Mannheim. In: SCHMITT, Carl. Ex Captivitate Salus. Esperienze degli anni 1945-47. Milano: Adelphi, 1987b. p. 15-26.

. La sapienza della cella. In: SCHMITT, Carl. Ex Captivitate Salus. Esperienze degli anni 1945-47. Milano: Adelphi, 1987c. p. 81-94.

. El Führer defiende el Derecho. El discurso de Hitler ante el Reichstag del 13 de julio de 1934. 1934a. In: AGUILAR, Héctor Orestes. Carl Schmitt, Teólogo de la política. México: Fondo de Cultura Económica, 2001. p. 114-118.

. El giro hacia el Estado totalitário. 1931. In: AGUILAR, Héctor Orestes. Carl

Schmitt, Teólogo de la política. México: Fondo de Cultura Económica, 2001. p. 82-94.

. El ser y el devenir del Estado fascista. 1929. In: AGUILAR, Héctor Orestes. Carl Schmitt, Teólogo de la política. México: Fondo de Cultura Económica, 2001. p. 75-81.

La teoría politica del mito. 1923. In: AGUILAR, Héctor Orestes. Carl Schmitt, Teólogo de la política. México: Fondo de Cultura Económica, 2001. p. 65-74. 
La noción de lo político. Revista de Estudios Políticos. nº 132, Nov.-Dic., 1963, p. 5-14.

. La revolución legal mundial. Plusvalía política como prima sobre legalidad jurídica y superlegalidad. Revista de Estudios Políticos, nº. 10, 1979, p. 05-24.

O Conceito do Político. Archiv für Sozialwissenschaft und Sozialpolitik. Vol 58, I, 1927, p. 1-33.

SCHWAB, Georg. Introduction. In: SCHMITT, Carl. Political Theology. Four Chapters on the concept of Sovereignty. Chicago: University of Chicago Press, 2006. p. 116.

. Carl Schmitt: Political Opportunist? Intellect. Vol. 103, No. 2363, February, 1975, p. 334-337.

STRAUSS, Leo. Notes on Carl Schmitt, The Concept of the Policital. In: SCHMITT, Carl. The Concept of the Political. Chicago \& London: The University of Chicago Press, 2007. p. 97-122.

STRONG, Tracy B. Foreword. In: SCHMITT, Carl. The Concept of the Political. Chicago \& London: The University of Chicago Press, 2007. p. IX-XXXI.

ZARKA, Charles Ives. Contre Carl Schmitt. Paris: PUF, 2004.

\footnotetext{
${ }^{1}$ Anschütz nasce em 10 e janeiro de 1867 e falece em Heidelberg, em 14 de abril de 1948, já quase ao final da Segunda Grande Guerra Mundial. Anschütz foi um notável professor de Direito Constitucional e um dos grandes interpretes da Constituição de Weimar, tendo escrito juntamente com Richad Thoma uma das obras de referência. O autor foi retirado de suas funções docentes quando da chegada ao poder dos nazistas, dados seus antecedentes ligados à democracia.

${ }^{2}$ A este respeito Schmitt é bem claro em um trecho em que se ocupa de delimitar sua área de intervenção teórica ao afirmar que "eu não falo aqui da cultura da humanidade na totalidade, nem do ritmo da história universal, e não sou capaz de dizer alguma coisa nem sobre os chineses nem sobre os hindus ou egípcios". (SCHMITT, 1992, p. 108).

${ }^{3}$ Este temor de Schmitt baseia-se na conexão de seu pensamento conservador com as restrições que estabelece aos princípios do otimismo e construtivismo de origem Iluminista. Como nos diz Strong, seu medo se deve a que "[...] all claims to good will recognize no limits to their reach". (STRONG, 2007, p. XXII).

${ }^{4}$ A este respeito é bastante elucidativa sua obra A essência e o valor da democracia (2006), a qual, a nosso ver, todavia se mostra apenas timidamente debatida em nossas faculdades de direito, em oposição à multicitada Teoria Pura do Direito.

${ }^{5}$ Bobbio trabalha este conceito de poder invisível em uma de suas obras. Ver BOBBIO, (2000). Neste sentido o próprio Schmitt retomando Cavour menciona trecho da obra deste em que a ideia ora apresentada em Bobbio torna-se presente:'Las plus mauvaise des chambres est encore prèférable a la meilleure des antichambres" (apud SCHMITT, 1999, p. 8). Na tradução: "A pior das câmaras ainda é preferível à melhor das antecâmaras". Ao trabalhar com esta concepção Schmitt explicita não desconhecer sérios e certos argumentos com os quais, a partir de 1933, iria, na prática, divergir, quando não mencionemos que em sua obra, já antes desta data, existiam elementos abertamente autoritários. Em sua crítica ao Parlamento Schmitt deixaria claro que naquela quadra histórica o "Parlamento parece mais uma enorme antecâmara diante dos gabinetes ou comissões de pessoas poderosas invisíveis". (SCHMITT, 1999, p. 8-9).

${ }^{6}$ Acurado trecho sobre a crítica schmittiana ao liberalismo foi escrito por Strauss. Ver STRAUSS, (2007, p. 99-101).

${ }^{7}$ Schmitt localiza a origem do conceito de soberania em um de seus filósofos prediletos, a saber, Jean Bodin. Desde logo, no autor o enfoque da soberania reside prioritariamente na dimensão do Estado, não
} 
precisamente no enfoque que lhe concederá Schmitt nos termos em que analisamos neste texto. Contudo, Schmitt retoma a velha definição aplicada ao Estado, a saber, de que se trata de um "poder máximo, juridicamente independente, não derivado" (SCHMITT, 1996b, p. 96) aplicável aos mais diversos interesses e esferas do político. Como sói no contexto de seus escritos, Schmitt realiza leitura interessada dos conceitos para fortalecer seus argumentos. No caso, Schmitt aproveita a ideia de soberania como um conceito "superlativo", designador de um "poder máximo" (SCHMITT, 1996b, p. 96), para logo aplicá-lo a sua teoria do poder soberano caracterizador de seu Estado totalitário.

${ }^{8}$ Schmitt ocupa-se em vários momentos das várias dimensões e problemas da questão da técnica. No Conceito do Político, por exemplo, Schmitt refere-se a que "as invenções técnicas são meios de uma enorme dominação das massas" (SCHMITT, 1992, p. 117) e, ainda mais, que o conceito de técnica apresenta-se de modo absolutamente neutro quanto aos fins em que pode ser utilizado, de sorte que pode tanto ser "revolucionária ou reacionária, servir à liberdade e à opressão". (SCHMITT, 1992, p. 117).

${ }^{9}$ No período posterior à Segunda Grande Guerra mundial Schmitt utilizará argumentos que não se oporão, como neste seu período intelectual dos anos 30, ao papel da mídia em sentido amplo. Ver SCHMITT, (1963, p. 11).

${ }^{10}$ Tal linha argumentativa viria, futuramente, a servir como material de combustão para os críticos da teoria da ação comunicativa habermasiana.

${ }^{11}$ Esta ingenuidade do espírito iluminista encontra constantes referências em Schmitt. Neste sentido, por exemplo, ver SCHMITT, (1992, p. 116).

${ }^{12}$ Neste sentido importa sublinhar a análise de Schmitt acerca de que as ideias políticas supõem uma perspectiva antropológica que, a rigor, divide entre duas, a saber, quem entende o homem como bom e aqueles que o veem como essencialmente mau. O Iluminismo encontrava-se conectado à concepção antropológica rousseauniana, a saber, de um homem bom ou, no mínimo, passível de aperfeiçoamento através de instrução. A sua derivação do raciocínio é de que o racionalismo construtivista presente no Iluminismo abriria as portas para um "despotismo legal", ou seja, que pudéssemos ter uma "humanidade inculcada e educada por um legislateur" ( $c f$. SCHMITT, 1996b, p. 123). Seu temor, contudo, não realizou-se seriamente por meio da pura perspectiva iluminista senão por intermédio da vertente totalitária dos regimes fechados que auxiliou a construir por meio dos argumentos reacionários e conservadores que desembocaria não em uma noção universalista de educação mas, isto sim, valendo-se da pura e simples justificação da eliminação física do dissidente ou de todos os que de alguma forma se manifestassem dissonantes da teoria nacional-socialista. A posição de Schmitt quanto a antropologia parece que deve ser identificada em ao menos três raízes. Uma das raízes de sua concepção parece encontrar-se em sua formação católica que identifica o homem como pecador original e, por conseguinte, abrindo a possibilidade de atribuir-lhe uma conduta pecadora e má por origem. A segunda das raízes de seu pensamento antropológico parece poder ser identificada na leitura da teoria política de Thomas Hobbes, onde sobressalta a concepção pessimista sobre a natureza humana. Em terceiro lugar, mas não menos importante, encontra-se a posição negativa ou altamente pessimista da natureza humana sustentada a este respeito pela tríade contra-revolucionária, a saber, De Maistre, De Bonald e Donoso Cortés ( $c f$. SCHMITT, 1996b, p. 124). A respeito de Donoso, por exemplo, diz Schmitt que "o seu desprezo pelos homens não tem limites: razão cega, a vontade débil, o elã ridículo das paixões carnais parecem-lhe deploráveis [...]" (SCHMITT, 1996b, p. 124), cujas massas são donas de vaidade tal que lhe tornam espantosamente tão estúpidas quanto seus próprios dirigentes ( $c f$. SCHMITT 1996b, p. 125). A título de conclusão sobre a influência conservadora na concepção de natureza humana em Schmitt encontramos sua citação de um trecho relativamente bem conhecido de Donoso Cortés que parece justificar uma série de aspectos da teoria jurídico-política schmittiana: "A humanidade é um navio que permanece à deriva com uma tripulação revoltada, ordinária, recrutada à força, que berra e dança, até que a ira de Deus jogue essa corja rebelde ao mar, para que o silêncio volte a reinar". (SCHMITT, 1996b, p. 125).

${ }^{13}$ A este respeito reiterava Schmitt que a angústia referente a situação espiritual do momento se justificava na medida em que "[...] com a técnica a neutralidade espiritual chegara ao nada espiritual". (SCHMITT, 1992, p. 117).

${ }^{14}$ Segundo uma tradução livre podemos dizer que terminus a quo significa ponto de partida ou termo a partir do qual, enquanto terminus ad quem significa ponto de chegada ou, secundariamente, limite ou termo até o qual.

${ }^{15} \mathrm{Em}$ um dos momentos em que Schmitt remete à análise do pluralismo, o faz na análise da teoria de Estado pluralista inglesa na figura de G. D. H. Cole e Harold Laski, cujo pluralismo, diz, consiste em "negar a unidade soberana do Estado, ou seja, a unidade política, e salientar reiteradamente que o homem individual vive em numerosas e diferentes ligações e agrupamentos sociais [...]". (SCHMITT, 1992, p. $66 ; 69-70)$. 
${ }^{16} \mathrm{Em}$ destes momentos a autora assente, referindo-se ao pensamento de Bobbio, de que "no debemos esperar el surgimiento de un tipo completamente nuevo de democracia y que las instituciones liberales han de permanecer" (MOUFFE, 1999, p. 145-146). Mouffe não poderia ser mais direta acerca de sua posição do que quando diz que "Bobbio tiene básicamente razón". (MOUFFE, 1999, p. 145).

${ }^{17} \mathrm{Um}$ destes aspectos em que a autora parece guardar distância de Schmitt está no valor que este concede ao papel da intervenção direta da população na consagração ou aclamação do líder político e de suas determinações que terminariam por convergir na vontade emanado próprio Führer de sorte a concluir todo o processo de legitimação de suas decisões. Assim, portanto, Mouffe concorda com o argumento apresentado por Bobbio quando este sustenta que o processo de democratização não deve ser conceber-se como se consentisse na transição da democracia representativa à democracia direta ( $c f$. MOUFFE, 1999, p. 145).

${ }^{18}$ Em algum momento Schmitt destaca que o significado atual daqueles contra-revolucionários encontrava-se na "conseqüência com que se decidem. Eles valorizam tanto o momento da decisão, que finalmente a ideia de legitimidade, da qual eles partiram, é suprimida". (SCHMITT, 1996b, p. 130). ${ }^{19}$ É interessante notar que o conceito de decisão Schmitt o constrói a partir do diálogo com um dos grupos de pensadores que mais lhe influenciaram, a saber, os contra-revolucionários, De Maistre, De Bonald e Donoso Cortés ( $c f$. SCHMITT, 1996b, p. 121). 